\title{
RF Module based Automated Toll Collection System
}

\author{
Somalatha $\mathrm{T}^{1}$, Anusuya $\mathrm{K} \mathrm{V}^{2}$, Salai Prajeetha $\mathrm{R}^{3}$ \\ \{181150@psgtech.ac.in'1 kva.ece@psgtech.ac.in², 181144@psgtech.ac.in $\left.{ }^{3}\right\}$ \\ Associate Professor ${ }^{2}$, Department of ECE, PSG College of Technology, Coimbatore. ${ }^{1,3}$
}

\begin{abstract}
In conventional systems of Toll Plaza, the operators collect the toll fee from the vehicle drivers and acknowledge it with a receipt. This manual process is timeconsuming and causing a longer waiting time for the vehicles to stay in the queue. In recent days, one of the advancements made in the Toll Collection system to reduce the waiting time of vehicles is the RFID FASTag method. It permits electronic payment and speeds up the toll collection process. This paper proposes a solution to overcome the drawbacks of the currently used RFID FASTag - such as double deduction of payment from the customer account and the physical damages to RFID FASTag. This method ensures the automated cashless quick transaction at toll centers with the assured single deduction of payment for the trip. Arduino IDE is used to program Node- MCU, having an in-built Wi-Fi facility to notify the owner about the location of the car.
\end{abstract}

Keywords: Cashless transaction, Liquid Crystal Display, Node-MCU, RF Transmitter, RF Receiver, Servo motor, Toll Plaza.

\section{Introduction}

The Government builds highways for better connectivity between the states and those costs lots of money. This is later recovered by charging the toll tax from people who use the highways. Traditionally, toll fee is collected manually via cash/ card payment at dedicated-toll booths. However, processing time at such plazas is extremely high due to manual intervention. This results in traffic jams and a huge concentration of vehicles causing inconvenience to travelers. This problem also leads to long waiting times, fuel inefficiency, and sometimes road rage, further leading to violence. Demand for faster and greater vehicle throughput has resulted in new concepts such as all-electronic, non-stop, open road tolling, etc.., The existing technology of cashless RFID- based system has the drawbacks of double deduction of epayment for toll fee and the physical damages of RFID Tag.

In this paper, an RF module-based automated toll collection system is proposed. The RF module used to transmit and receive the signals between the vehicles to the toll booth is placed inside the vehicle. This minimizes the chances of its physical damages. With the use of a switch inside the vehicle, the fee transaction is completely brought under the control of the client (vehicle). This technique avoids the double (or multiple) time e-payment of toll fees.

This solution supports modern-day digital technologies that safeguard toll revenues. Besides replacing manual cash collections, it provides an enhanced customer experience by improving mobility, increasing safety, and adding convenience. Electronic toll collection technology identifies whether the vehicles passing are enrolled in the program, alerts those are not, and electronically debits the accounts of registered users without requiring them to stop, eliminating inconvenient manual payment methods. 


\section{Literature Survey}

In paper [1], the RFID-based system implementation is divided into the design of two modules- the Vehicle Module (Active Tag) and the Base Module. The two modules communicate via an RF modem connected to each module. The base module comes with a user interface that allows the administrator to monitor the current activities in the range, including the vehicles in the range, their status, and detailed information about any registered vehicle. The cost of implementation for this project proposed here is higher than the options available in the market. This is due to the increased capabilities incorporated into the system to counter the problems of scalability, power requirements, and shielding effects.

This paper [2], deals with the Automated Toll collection and Check-Post system using Radio Frequency Identification (RFID) and Global System for Mobile communications (GSM) module. The RFID tag is rupturable and there may be chances that it may be lost. Also, double detection of the ID may happen so that the money will also be detected twice. In the paper [3], there may be a chance the scanning mechanisms are not able to read a FASTag. In this case, someone has to be technically sound to troubleshoot such issues. In rare cases, the FASTag might become unreadable after a few transactions. The government or issuer has to have a backup plan to reissue the same to the customer. In paper [4], the FASTag is a simple sticker that is placed on the inside of the windscreen. Under any circumstances, may this FASTag gets tampered with or damaged, it would result in another trouble to the customer. It may become unusable, which means, it must be repurchased another FASTag for your vehicle. Though the money is refundable, one has to go through the registration process again. And since RFID tags are deployed the heavy or oversized vehicles take the advantage of using the RFID tags of 2-axile vehicles.

And since RFID tag is deployed the heavy or oversized vehicles take the advantage of using the RFID tags of 2-axile vehicles. In the journal paper [5] a method is proposed to transform manual transactions to automated toll collection with the help of RFID technology. In the system [6] if the authority wants to block a certain type of vehicle or a specific vehicle, it can be done at the toll booth area.

\section{Proposed Methodology}

The overall system view shown in Fig. 1 overcomes the disadvantages mentioned. The pressing of the button initiates the whole process and is interfaced with the Node MCU. When the car nears the toll, the button is pressed and the RF transmitter placed inside the car transmits the Engine number of the car. Since the RF transmitter inside the car and the RFreceiver in the toll are within a distance of $50 \mathrm{~m}$, the reception takes place effectively. The microcontroller board Nodemcu ESP8266 is programmed [8] according to the datasheet [7] and its specifications. 


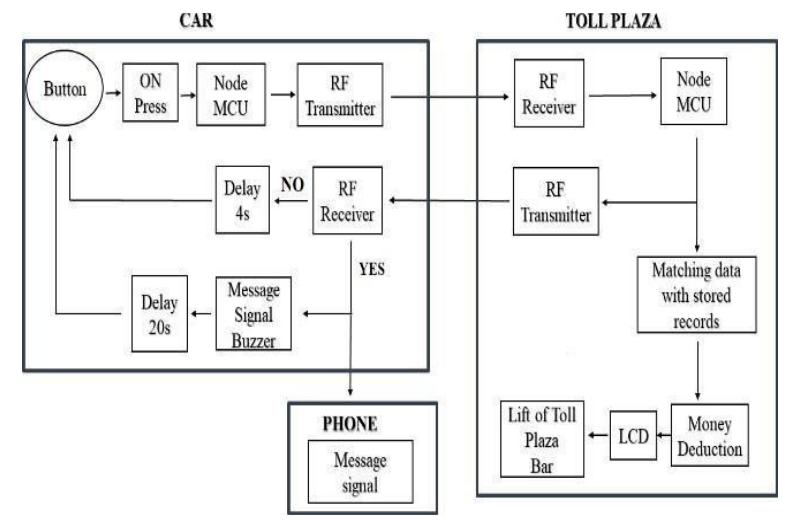

Fig. 1. Overview of the Proposed System

\section{Proper reception at Toll Plaza}

When the RF receiver in the toll receives the engine number of the car, the matching process begins by comparing the received data with the database to obtain the bank account linked with the Engine number. The toll fee amount is then deducted from that account. An acknowledgment is sent from the RF transmitter of the toll and is received by the RF receiver inside the car. The owner whose mobile number will be registered need not drive the car always. Hence, the acknowledgment from the toll turns on the buzzer which is placed inside the car indicating the completion of the toll fee payment to the person who is

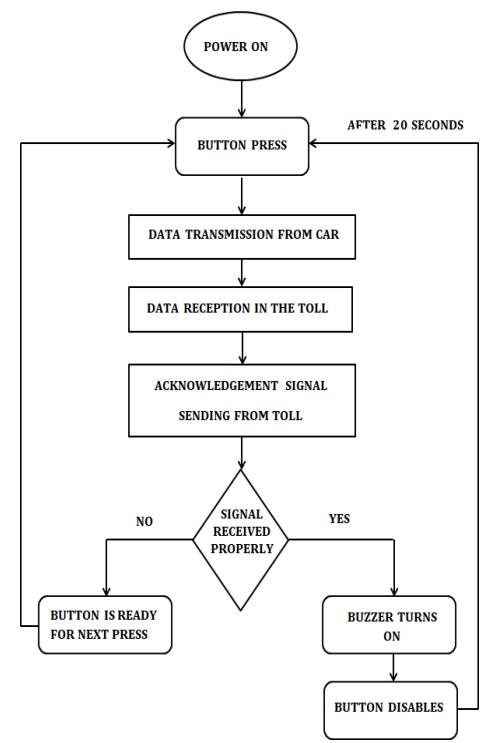

Fig. 2. Workflow of the proposed automated system 
driving. Also, a message is sent to the registered mobile number. The signal from the button press is then disabled for few seconds to avoid double deduction (that is, even if the client unknowingly presses the button, the RF transmitter inside the car stops the transmission of signals for the next 20 seconds). The deducted amount is displayed on the LCD and the toll plaza bar is lifted with help of a servo motor.

\section{No/Improper reception at the Toll plaza}

When the RF receiver in the toll is not received with the signal (if the client has pressed but the RF receiver is not in the range of $50 \mathrm{~m}$ or for any other reasons), then the RF transmitter transmits a logic 0 as a negative acknowledgment. Hence, the RF receiver inside the car enables the button to be pressed again for proper transmission after which the same procedure of "Proper reception at Toll Plaza" occurs.

\section{Implementation}

The workflow of the proposed system is shown in fig. 2 . The process is initiated once the button is pressed when it nears the toll plaza effectively when the distance is less than 50m. The data (unique engine number) is transmitted. Toll plaza receives the data and it sends the acknowledgment that whether the data is properly received or not. If properly received, the buzzer in the car buzzes and the button is disabled for the next 20 seconds which prevents the double deduction. If the proper reception has not taken place, the button will be ready for the next press and the procedures mentioned above will be continued.

\section{A. Transmission of Data from Car}

The transmitter and receiver module is tested and the transmitter module is interfaced with the ESP8266 board and with the RC Switch library installed. The code is dumped into the board and the engine number of the car is transmitted. The button is then connected and the transmission is controlled. Only after the button press, the data transmission is enabled. The code for this process is shown in Fig 3.

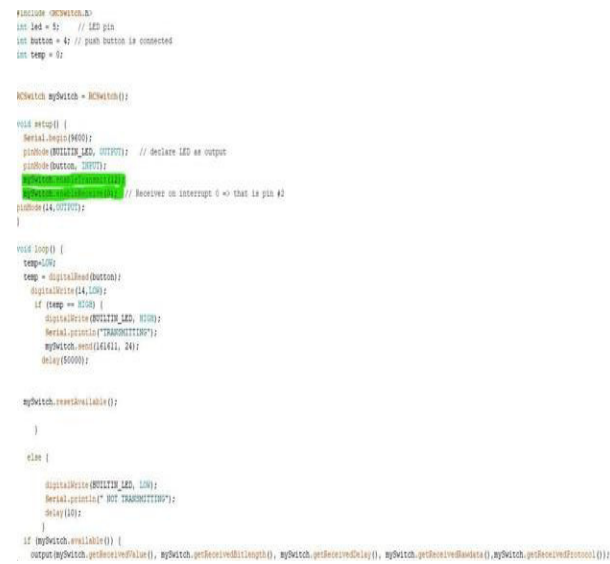

Fig. 3. Transmission of Data- engine number from car. 


\section{A. Reception of Data at Toll}

The data transmitted from the car is received by the receiver module interfaced with another ESP8266 which is shown in Fig 4. The same RC Switch library is used for the reception of data at the toll side and the received data is printed on the serial monitor.

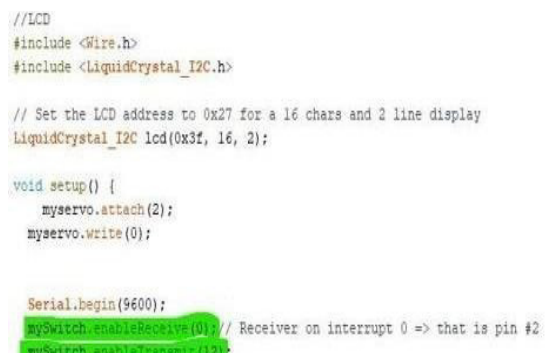

Fig. 4. Reception of Data at toll

B. Matching Process

The received data is compared with the previously stored records (database) and if it matches, the account number linked with that data is accessed and the amount is deducted from that account number based on the type of vehicle. The process is shown in Fig 5. The account number and the balance in that account number are stored previously in the database.

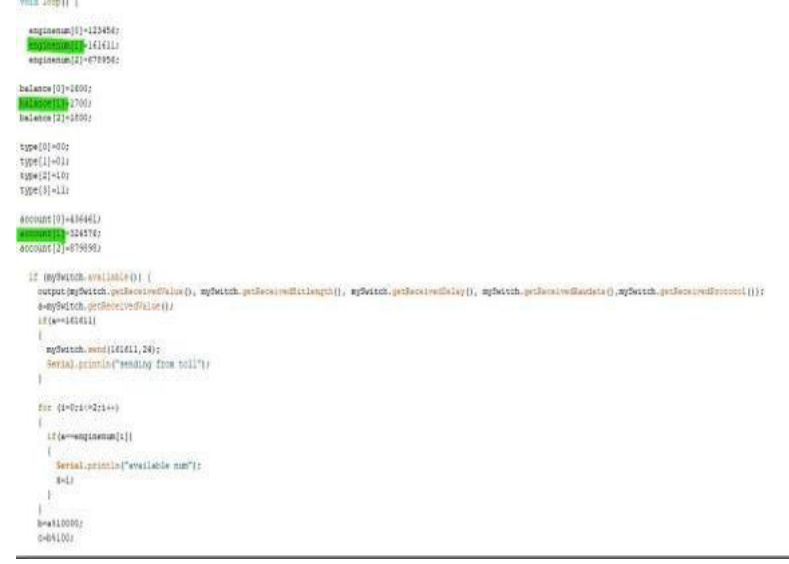

Fig. 5. The matching process at toll

\section{SMS Reception}

Once the data has been received and the amount gets deducted, the node MCU triggers an SMS to the registered mobile number of the corresponding engine number with the help of IFTTT and ESP8266Wifi library. The mobile number registered will be uploaded along with the code. The SMS delivers the message stating that the car has crossed the toll. The code is shown in fig6. 


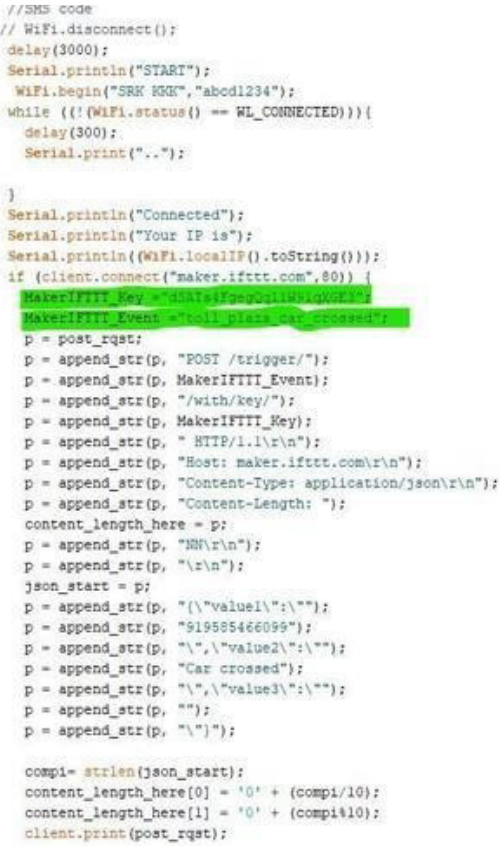

Fig. 6. SMS Reception to the users mobile

D. Displaying the Amount In LCD

When the amount is deducted from the registered bank account, the amount deducted is displayed in the LCD by interfacing it with node MCU provided the code below with the library LiquidCrystal_I2C.The process is shown in Fig 7. Since the LCD is placed in the line of sight of the car, the amount displayed in it is seen clear enough by the person in the car.

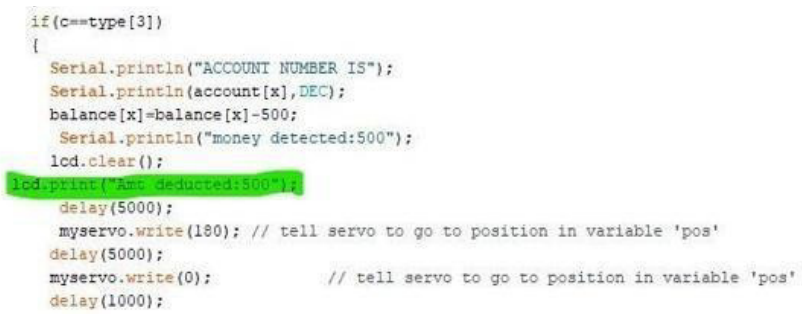

Fig. 7. The amount deducted displayed in the LCD

\section{E. Lift of Toll Plaza Bar}

The toll bar is lifted with the help of a servo motor. The servo motor is rotated 90 degrees and then brought to the initial position after some delay. This is done by interfacing the servo motor with ESP8266 and the below code dumped with the help of the Servo library. The code is shown in fig8. 


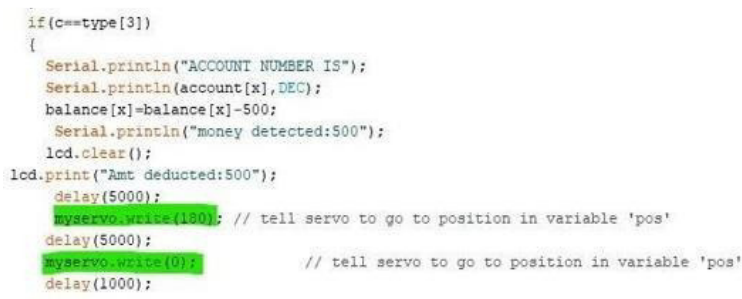

Fig. 8. Toll plaza bar lifting 180 degree

F. Retransmission of Received Data to Car

When the data is received in the toll via the RF receiver, an acknowledgment signal is transmitted back to the car, to indicate that the data sent from the car has been properly received in the toll.

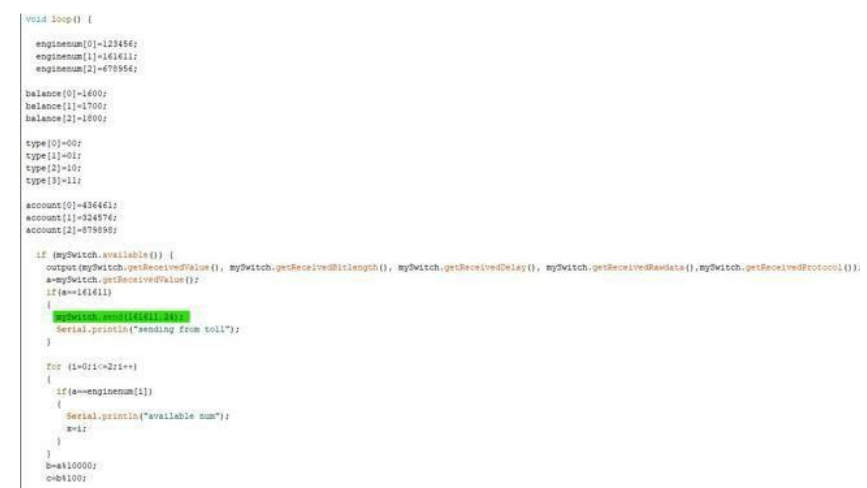

Fig. 9. Transmission to the car to ensure proper reception

\section{G. Data Reception in the Car}

The signal sent from the toll is received by the RF receiver in the car which turns on the buzzer in the car to indicate that the data sent from the car is properly received in the toll. And the button in the car is disabled for the next few seconds to avoid another press which may lead to a double deduction of the amount. The code for data reception is shown in Fig 9 and the acknowledgment is shown in Fig10.

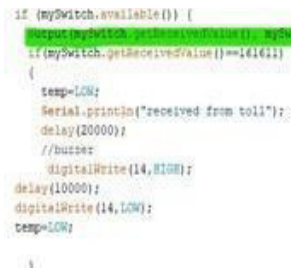

Fig. 10. The reception of data at the car as acknowledgment 
The circuit connections at the car side and toll side are shown in Fig11.1 and 11.2. The implementations are shown in Fig12 \&13.

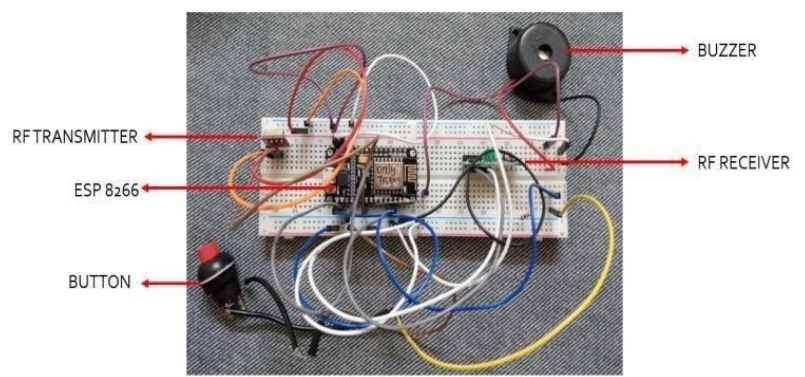

Fig. 11.1 Circuit Connection - Car Side

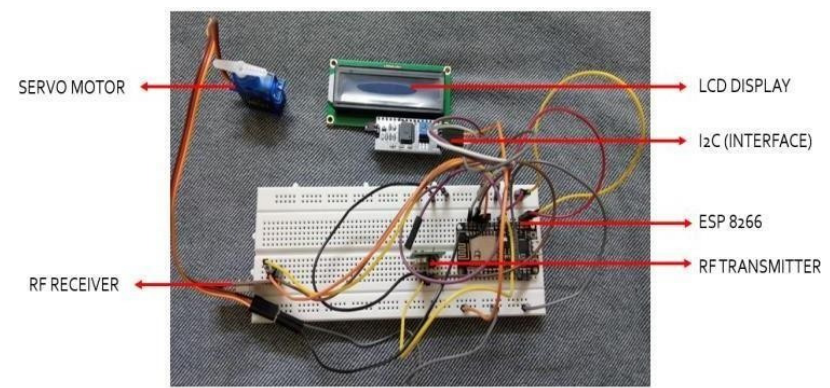

Fig. 11.2 Circuit Connection - Toll Side

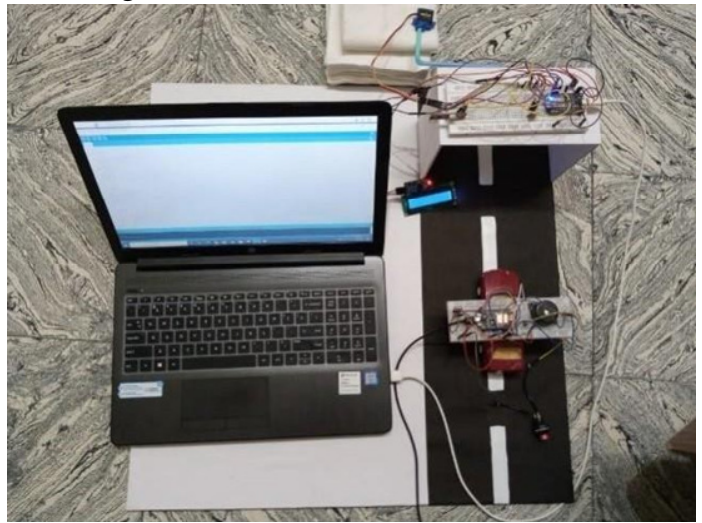

Fig. 12 Top view of the implementation of the proposed system 


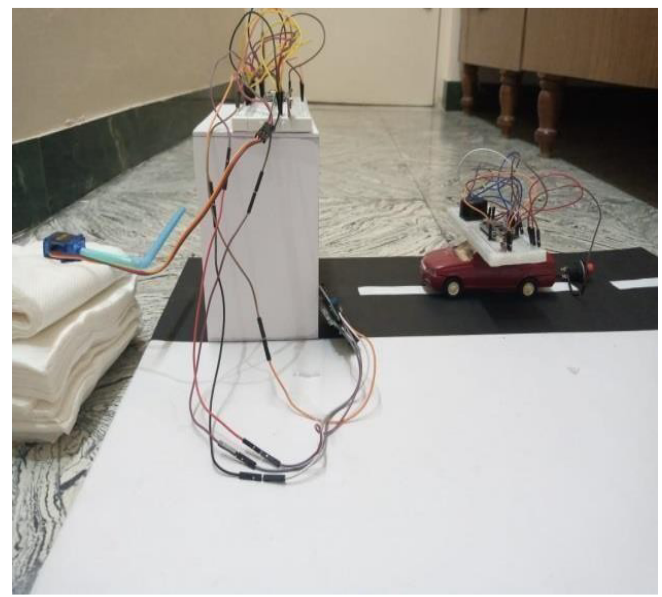

Fig. 13. Side view of the Implementation of the Proposed System

\section{Result Analysis}

The Node MCU in the car is interfaced with an RF transmitter so that the data to be transmitter which the unique engine number of the car is fed to the Node MCU and by interfacing Node MCU with the RF transmitter, this data can be transmitted. The transmission of data is controlled by a push-button. When the button is pressed, the data is being transmitted.

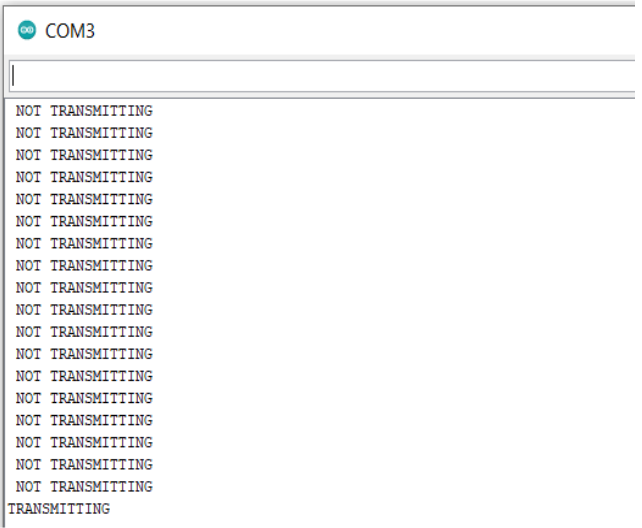

Fig. 14. The RF transmitter transmitting once the Button is pressed. 


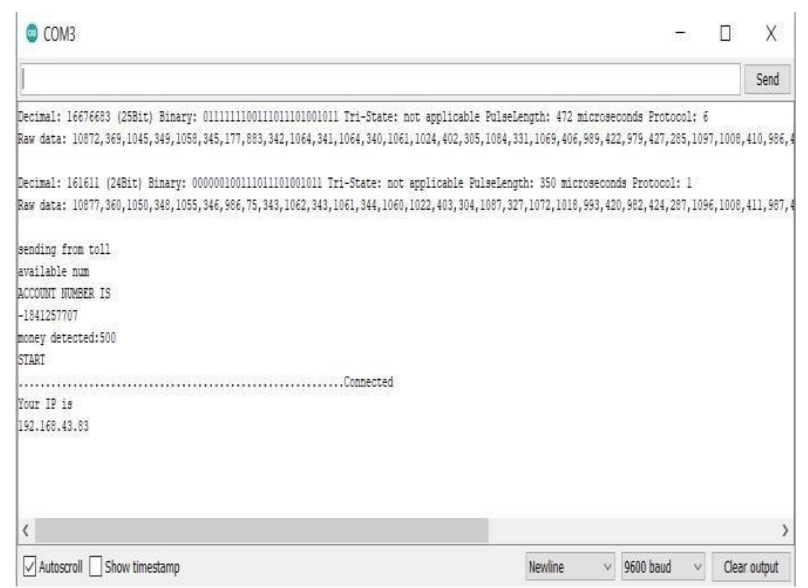

Fig. 15. The serial monitor (details of transaction displayed)

The data signal transmitted by the RF transmitter of the car as shown in Fig. 14. is received by the RF receiver when the car moves nearer to the toll. When the signal is received, a particular amount will be deducted from the registered bank account and an SMS is sent to the mobile number linked with the account. The details of the transaction performed are shown in Fig. 15. the amount deducted for the particular vehicle is displayed to the user with an LCD interfaced with ESP8266 by I2C as shown in Fig 16.

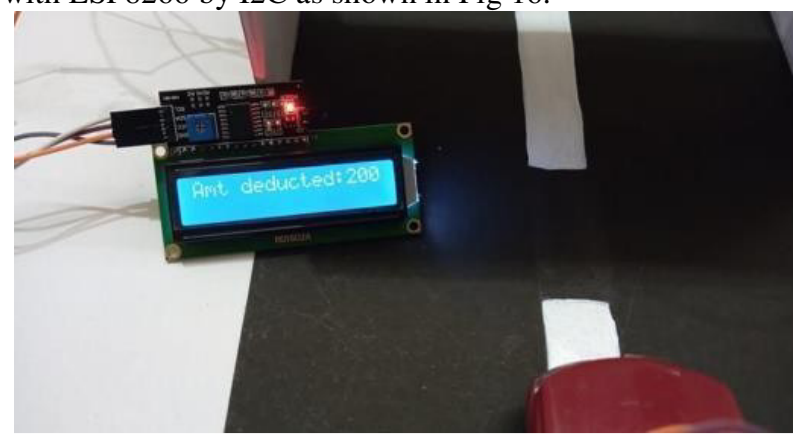

Fig. 16. The LCD displaying the amount deducted 


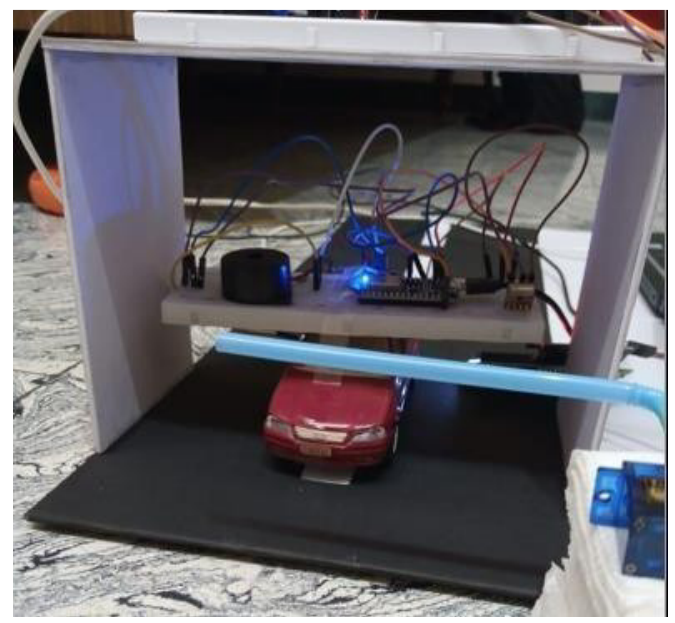

Fig. 17. The servo motor rotating 180 degree

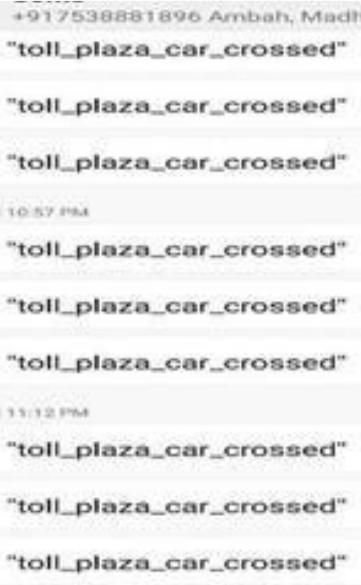

Fig. 18. SMS Received at the Registered Mobile Number

The toll plaza bar is lifted by using a servo motor, which is rotated to 180 degrees and after the car passes through, the bar returns to the same position. The SMS received by the user is shown in Fig. 18. To ensure that the signal is properly received, an acknowledgment signal is sent from the RF transmitter interfaced with the Node MCU. The signal transmitted by the RF transmitter of toll is received by the RFreceiver in the car. When the signal is received, a buzzer connected to the Node MCU turns on to indicate that the signal has been properly received. And the button will be disabled for the next twenty seconds to avoid a double deduction. 


\section{Conclusion}

The problems addressed in this paper are to avoid double-time deduction, usage of RF modules to avoid damages caused to RFID tags. The approach of the proposed framework is as achieving control over a transaction is achieved using a button. The establishment of communication between Toll and car using RF module which overcomes the damages caused to RFID labels are done. Using the buzzer and message facility, the transaction is indicated to the user as well as the worker at toll. After all the procedures the servo motor is used to lift the toll bar. For easiness, the amount deducted is displayed using a liquid crystal display in the view of the sight of the driver. The Google Assistant feature can be merged with the system to have ensured control over the transaction. The use of a Global Positioning System instead of manually pressing the button to transmit the signal can also be included to increase the easiness. The location of the registered vehicles is provided at the toll so that the vehicle which getting near the toll automatically starts sending the data signal view of the sight of the driver.

\section{References}

[1] Atif Ali Khan, Adnan I. ElberjaouiYakzan, MaarufAli, "Radio Frequency Identification (RFID) Based Toll Collection System" International Conference on Trends in Engineering and Technology, pp. 103-107, January 2017.

[2] K. Balamurugan, Dr.R. Mahalakshmi, Dr.S. Elangovan, R. Pavithra, "Automatic Check-Post and Fast Track Toll System Using RFID and GSM Module with Security System” in International Carnahan Conference on Security Technology (ICCST), pp. 83-87, October 2017.

[3] Dr.A.Amutha, Kiruthika. R, Annapoorani. B, Preethi. A Priyanga. P, Inderjeeth.M, "Rfid And Gsm Module Based Automated Toll Plazas On Highways" in International Journal of Advanced Research in IT and Engineering, vol. 5, pp. 352-357, 2017.

[4] Vishnupriya. R, Dr.N.P.Ananthamoorthy, "Automatic Toll Collection System Using RFID \& GSM Technology" in International Journal of Pure and Applied Mathematics, vol. 118, pp. 421424, October 2017.

[5] AungMyintWin, Chaw MyatNwe, KyawZinLatt, "RFID-Based

[6] Automated Toll Plaza System" in International Journal of Scientific and Research Publications, vol. 4, June 2014.

[7] Rafiya Hossain, Moonmoon Ahmed, Md. Mozadded Alfasani, Hasan U. Zaman, "An advanced security system integrated with RFID based automated toll collection system" in Third Asian Conference on Defence Technology (3rd ACDT), pp. 59-64, January 2017.

[8] Datasheet:https://components101.com

[9] CircuitDigest-Wi Fi:https://circuitdigest.com /microcontroller- projects/sending-sms-using esp8266. 